\title{
Advancement towards an approved vaccine to target Plasmodium falciparum malaria
}

\author{
Andrew W. Taylor-Robinson \\ School of Medical \& Applied Sciences, Central Queensland University, Rockhampton, Australia
}

\section{Email address:}

a.taylor-robinson@cqu.edu.au

\section{To cite this article:}

Andrew W. Taylor-Robinson. Advancement Towards an Approved Vaccine to Target Plasmodium Falciparum Malaria. International Journal of Immunology. Vol. 2, No. 5, 2014, pp. 31-39. doi: 10.11648/j.iji.20140205.11

\begin{abstract}
Plasmodium falciparum causes the severest form of malaria which kills well over one million persons each year, chiefly children, and results in significant debilitation in hundreds of millions more. This disease has a dramatic socioeconomic impact in endemic countries and thus it is a recurring target for global health enterprises. Increased investment in existing control measures, including insecticide-impregnated bed nets, has been paired with revitalized efforts to develop an efficacious vaccine. Sequencing of the genome of $P$. falciparum has provided insights into the malaria parasite's complex lifecycle, which, combined with a deeper understanding of the human immune response to infection, has yielded many novel candidate vaccines during the past two decades. Most notable of these is RTS,S which has shown great promise over a long development process, becoming the first candidate vaccine against human malaria to advance to phase III clinical trials. Hence, there is optimism that in the near future RTS,S may become the first ever licensed vaccine against a parasitic disease in humans. However, this is qualified by the need for a better knowledge of its mechanism of protection and questions raised over its long-term therapeutic capacity. While the availability of RTS,S as a validated commercial product is not guaranteed, it is likely to contribute to the continuing campaign against malaria, if only as a forerunner to a fine-tuned second generation vaccine.
\end{abstract}

Keywords: Plasmodium Falciparum, Malaria, Immunity, Vaccine, RTS,S

\section{Introduction}

In humans malaria is caused by five species of protozoan parasite of the genus Plasmodium which are transmitted by Anopheles mosquitoes. ${ }^{1,2}$ The disease is endemic to all continents apart from Antarctica, but is confined principally to tropical regions. ${ }^{3,4}$ Of a world population of around 7.1 billion people, ${ }^{5} 3.4-3.7$ billion are at risk of contracting malaria. ${ }^{3,6}$ It is standardly claimed that there are 300-500 million clinical cases worldwide annually. ${ }^{7}$ The 1-3 million deaths that result equate to a death each $10-30$ seconds. ${ }^{8,9} 90 \%$ of deaths are due to $P$. falciparum and occur mainly in young children in sub-Saharan Africa. Pregnancy-associated malaria results in $75,000-200,000$ infant and maternal deaths a year. ${ }^{10}$ Disease is distributed mainly among socio- economically lower developed nations, further exacerbating their cycle of poverty. The estimated cost to endemic countries is US \$12 billion per annum. ${ }^{3,11}$ An annual reduction of $1.3 \%$ in economic growth may be attributed in part to lost person hours and therefore to lessened productivity. ${ }^{12}$ Moreover, children missing school experience impaired education that affects their prospects of future employment.

These figures testify to a public health calamity. An efficacious, economical vaccine against $P$. falciparum, or the debilitating and often life-threatening effects infection with this parasite causes, is considered a holy grail of modern molecular medicine. ${ }^{13}$ Clinical studies have regularly linked immune responses to antigens expressed by liver and blood stage parasites with resistance to infection or disease, thereby providing a persuasive argument to develop anti-malaria vaccines. By dissecting mechanism(s) of immunity to antigens, we can optimally evaluate in various delivery systems epitopes associated with protection as components of a focused and coordinated multi-antigen malaria vaccine strategy. This review considers impediments to effective vaccine design exhibited by the parasite and highlights key concerns which need to be addressed surrounding potentiation of a putatively protective immune response. Prospects for current development pathways, notably RTS,S, are discussed. 


\section{Plasmodium Life Cycle and Disease Pathophysiology}

All Plasmodium species that infect humans have a multi-stage life cycle which is essentially similar. Variations in requirements for host cell invasion of each species result in different aetiologies and thus distinct clinical presentations. An individual is infected following inoculation with Plasmodium sporozoites contained in the saliva of a female Anopheles mosquito when it takes a blood meal. When sporozoites enter the peripheral blood they localise directly to the liver, invade hepatocytes and perform asexual reproduction (hepatic schizogony) to generate intracellular liver schizonts. ${ }^{14-16}$ A quiescent form of parasite, the hypnozoite, also exists within hepatocytes for $P$. vivax and $P$. ovale but not $P$. falciparum. ${ }^{14,17}$ Hypnozoites are responsible for persistence of infection when malaria relapses after the original challenge has been cleared. ${ }^{18}$ This pre-erythrocytic stage of the life cycle has been the target of most vaccine research so far. ${ }^{15}$

Thousands of merozoites are discharged into the blood upon schizont-infected hepatocyte rupture. These invade erythrocytes and go through another asexual reproductive cycle (erythrocytic schizogony). ${ }^{14,16}$ Merozoites metabolise haemoglobin and develop into trophozoites, then schizonts. When each erythrocyte bursts, further merozoites are released, increasing greatly the parasitaemia, the parasite load of the blood; this induces the manifestations of acute uncomplicated malaria. ${ }^{14,15}$ Typical clinical signs are of febrile paroxysms, which are fevers consisting of three stages - a cold stage (cold, rigors), hot stage (spiking temperature) and sweating stage. ${ }^{14}$ In the instance of $P$. falciparum, this cyclic fever continues for 46-48 hours, separated by brief period when the host feels somewhat better before another cycle starts. Paroxysms are cytokine-induced and relate directly to erythrocyte rupture. ${ }^{17}$ Fever is commonly accompanied by other indications including headache, myalgia, malaise, confusion, anxiety, and hepatosplenomegaly as a result of engorgement with infected erythrocytes. $^{14,16}$

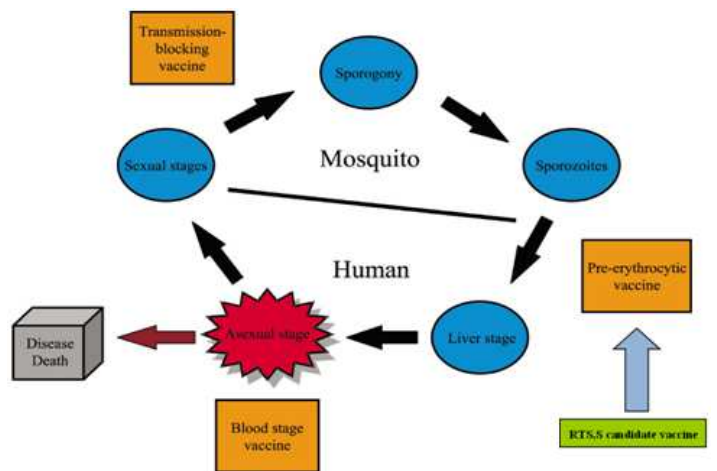

Fig. 1. Schematic life cycle of Plasmodium falciparum, indicating where vaccination may be predicted to intervene. A pre-erythrocytic candidate, such as the RTS,S vaccine, targets the parasite prior to release of asexual stages into the blood, thereby potentially preventing disease pathology.

Fig. 1 illustrates the life cycle of $P$. falciparum and signifies the three stages that provide targets - pre-erythrocytic vaccines, blood stage vaccines and transmission-blocking vaccines (prevent sporogenic cycle). There is temporal expression of many stage- specific antigens which candidate vaccines are designed to target. Severe $P$. falciparum infection (complicated malaria) can present in several ways including cerebral malaria (cytoadherence of infected erythrocytes within the vasculature of the brain with neurological sequelae) severe anaemia, renal disease and pulmonary oedema, and these complications collectively cause the majority of deaths. ${ }^{16}$ Hence, the rationale for pre-erythrocytic vaccine development is the elimination of infection before release of parasites into the blood with which morbidity and mortality are associated.

\section{Global Efforts to Control Malaria - Past and Present}

Extensive strategies to control malaria have a chequered history, successful in some regions of the world but stuttering poorly in several others, and best practice continues to be ignored. ${ }^{19}$ There are many ways to prevent or reduce the risk of contracting infection, and elimination and ultimately eradication are regarded as theoretically possible using currently recommended preventative measures. These strategies include: prevention through mosquito vector control and use of long-lasting insecticide-impregnated bed nets and, where appropriate, indoor residual spraying with insecticides; seasonal malaria chemoprevention as advised; intermittent preventive treatment in pregnancy and for infants; rapid diagnostic testing; and treatment of confirmed cases with effective anti-malarial drugs. ${ }^{20}$ These low technology tools have lessened significantly the disease burden attributable to $P$. falciparum in some areas of Africa and will continue irrespective of any possible delivery of a first-generation malaria vaccine. Nonetheless, malarious areas occur predominantly in developing countries where the economic resources to implement effective and sustained nationwide coverage are frequently insufficient. Moreover, poor education, inadequate living standards and malnourishment, for example, worsen the dilemma. There are also problems related to drug resistance by the parasite and insecticide resistance by the mosquito caused by selection pressures introduced through their overuse and misapplication. ${ }^{21}$

\section{Urgent Need for a Malaria Vaccine}

Substandard operational management and not the quality of cost-effective control measures as such is ultimately liable for the failure to eradicate malaria. While currently not yet available, therefore, a licenced vaccine may provide a singular prospect of eradication; this international public health aspiration was achieved for smallpox, which provides an exemplar for all infectious diseases. Informed construction of a malaria vaccine is predicated on knowledge of natural immune responses, then artificially potentiating protective 
immunity to immunogenic antigens. When a candidate is identified, it commences on a protracted pathway of formulation, enhancement and testing in clinical trials.

Over the past decade, a revival of public interest in the 'malaria problem' prompted an extra resolve to utilise new and existing control measures. This provoked The Bill and Melinda Gates Foundation (BAMGF) in 2007 to declare that eradication should be targeted once more. ${ }^{19,22}$ Swift support from the World Health Organization (WHO) led to the establishment of the Malaria Elimination Group, whose goal this now is. Moreover, in 2004 the Program for Appropriate Technology in Health (PATH) drove the formation of the Malaria Control and Evaluation Partnership in Africa. ${ }^{23}$ This liaises with the continent's governments and the Roll Back Malaria partnership to deliver preventive and control interventions.

Conceived by a consortium of the world's foremost health organizations including the WHO, BAMGF and the Wellcome Trust, in 2006 the Malaria Vaccine Technology Roadmap was produced. This defined a very challenging new goal to manufacture a vaccine by 2025 that has a protective efficacy of at least $80 \%$ against clinical disease caused by $P$. falciparum and which persists for over four years. ${ }^{23}$ An intermediate milestone was set down that by 2015 the vaccine should be $50 \%$ effective against severe disease and death and should last in excess of 12 months.

\section{Immunity to Infection Authenticates Vaccine Design Principles}

\subsection{Correlation with Exposure}

The immunity to $P$. falciparum elicited by humans in endemic regions develops slowly and is ascribed to the parasite's poor intrinsic immunogenicity and noted antigenic polymorphism which compels immunity to be strainspecific. $^{24,25}$ Duly, this entails cumulative exposure to multiple variants of a particular species which generally requires the first twenty years of life to develop completely. ${ }^{24,26}$ Infections are more severe in children, in which most malaria-related mortality occurs. ${ }^{4,27}$ In endemic areas, $P$. falciparum infection in children of under 5 years of age can lead to severe disease and is the cause a quarter of juvenile deaths in Africa. Cerebral malaria and respiratory distress, the most severe manifestations of disease, share several features in common with uncontrolled inflammation or sepsis. These may be investigated through judicious application of well-defined experimental models. ${ }^{28}$ In addition, pregnant women exhibit heightened susceptibility, in part due to the placenta presenting a novel adult tissue to which pregnancy-associated parasite variants that express the VAR2CSA antigen adhere to the surface of syncytiotrophoblast cells by specific binding to chondroitin sulphate A. ${ }^{29}$ Parasite accumulation, and attendant inflammation, disturbs the cytokine equilibrium of pregnancy with the potential to induce placental damage, compromise foetal growth and prompt preterm delivery. Immunity to placental malaria parasites develops in a gravidity-dependent fashion which limits unfavourable pregnancy outcomes in multigravid women. ${ }^{29,30}$

As a generalisation, recurrent exposure invokes non-sterile immunity by which people have a low level parasitaemia but show few or no symptoms of disease; this is often referred to as stable malaria. ${ }^{31,32}$ Although the adult immune system can control infections, an asymptomatic individual may act as a reservoir of infection. Moreover, immunity abates rapidly unless a person is infected repeatedly, making maintenance of immunity imperfect. ${ }^{31-33}$ Persons with waning immunity or irregular infection thus have unstable malaria. ${ }^{4}$ These reasons highlight further the requirement for an effective vaccine which would induce sterile immunity, i.e. a total absence of the parasite from a would-be host, achieved without prolonged exposure and debilitating illness.

\subsection{Identifying Shortfalls in Knowledge}

Since residents of regions endemic for $P$. falciparum acquire immunity to 'mild' or 'uncomplicated' malaria only following several years' exposure to multiple bites from infectious mosquitoes several key questions may be raised in regard to the nature of a protective immune response. In order to valuably instruct effective vaccine design, the cardinal issue of what constitutes immunity to $P$. falciparum requires elucidation. Specifically, answers are needed to these questions:

- Of more than 5400 gene products encoded by $P$. falciparum which ones are targets of innate and adaptive immune responses?

- Do any of these products impede attainment of immunity, and how does this arise?

- Why does immunity take so long to develop?

- How does the frequency or persistence of infection affect generation of protection?

- How long does immunity last, and by what mode, in the absence of continuing parasite exposure?

- Are identical or related mechanisms involved in protection from mild and severe malaria?

- How do multigravid women establish parasite- specific immunity which averts adverse pregnancy outcomes?

- How are P. falciparum infection and acquisition of immunity influenced by contemporaneous secondary antigenic stimulation such as through superinfection with an antigenically variant isolate of $P$. falciparum, or with the individual's own microbiota, or by co-infection with other pathogens, e.g. HIV/AIDS, tuberculosis or schistosomiasis?

- If a vaccine elicits partial protection, is there a difference between the immunity it engenders and that induced by natural $P$. falciparum infection, and if so, is this significant?

- Is there a particular immune response elicited by a malaria candidate vaccine which provides an authentic correlate of protection?

- Is there a molecular marker induced initially by vaccination that predicts accurately the subsequent quality, magnitude and longevity of protective effector 
and memory responses?

Insight into all these queries will inform the optimal construction of a malaria vaccine. An ideal vaccine would have significant efficacy in all ages of recipient, be reliable to administer, safe inside the host and not have any serious side-effects. ${ }^{34}$ It should also replicate, or even better, enhance naturally acquired immunity and be long-term without boosters or interference from other vaccines. ${ }^{35}$ Finally, it should be economical to manufacture and purchase. Regrettably, it is doubtful that malaria vaccines will fulfil all of this 'wish list' of attributes. Rather, it is more likely that they will be moderately effective, confer short-term immunity and be challenging and costly to manufacture. ${ }^{34-36}$

\section{Malaria Vaccines - Current Status}

Due to the deficit in performance of other malaria control measures, raised awareness of vaccines led to the formation in 1999 of the PATH Malaria Vaccine Initiative (MVI), a non-government organization (NGO) based in Washington DC, USA, that facilitates accelerated testing of malaria vaccines. ${ }^{37}$ At present, there are 60 -odd documented malaria vaccine candidates, including 41 in preclinical and clinical trials. $^{38}$ Four vaccines are currently supported by MVI in clinical development (Fig. 2).

Vaccine candidates aimed at the pre-erythrocytic stage target either sporozoites or intrahepatic parasites. ${ }^{39}$ Designed to elicit sterile immunity against antigens present on inoculated sporozoites or expressed by schizont-infected hepatocytes, their effectiveness is predicated on blocking hepatocyte invasion and thus the development of merozoites, which would otherwise invade erythrocytes. ${ }^{16}$ With a relatively long period within which to operate (seven days for $P$. falciparum) and few infectious organisms with which to deal, this a promising stage to target. ${ }^{40}$ As it is a clinically silent stage an effective vaccine would both halt transmission and prevent clinical symptoms developing.

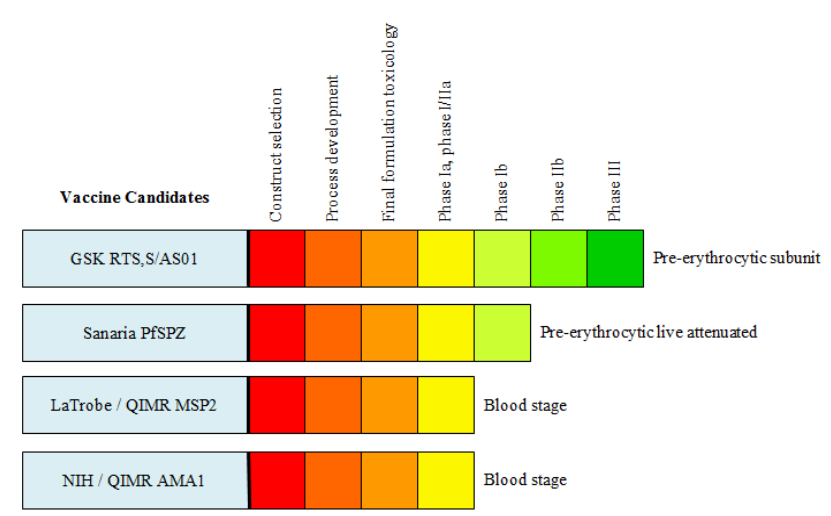

Fig. 2. Schematic illustration showing the advanced progress of RTS,S in comparison to development of other leading malaria candidate vaccines.

In 2001, MVI reached an agreement with Glaxo SmithKline (GSK) to develop a promising candidate vaccine against $P$. falciparum called RTS,S, which was first generated in 1987 in collaboration with the Walter Reed Army Institute of Research. ${ }^{41}$ Founded on the circumsporozoite protein (CSP) that coats the surface of $P$. falciparum sporozoites and which is associated closely with effective human immune responses, ${ }^{42}$ RTS,S has been shown to induce sterile immunity in malaria-naïve and semi-immune individuals. By 2006, a further \$207.6 M had been invested which has helped advance trials of the RTS,S/AS01 formulation. ${ }^{41}$ In March 2009 , this became the first vaccine to advance as far as phase III clinical development (Fig. 2). ${ }^{9}$

\section{Development of RTS,S}

\subsection{Molecular Structure}

RTS,S is a hybrid molecule comprising two recombinant segments (RTS and S) co-expressed in a yeast cell. ${ }^{43}$ RTS contains three distinct portions, the first of which is a single polypeptide chain that corresponds to a large region of the highly conserved tandem repeat $(\mathrm{R})$ tetra-peptide sequence from CSP; each repeat tetra-peptide is called NANP. ${ }^{44,45}$ There are 19 copies of NANP and it is named for its amino acid sequence.

The second portion is the $\mathrm{T}$ lymphocyte epitopecontaining ( $\mathrm{T}$ ) flanking region on the $\mathrm{C}$-terminus; this is made up of highly conserved amino acid sequences separated by immunodominant effector $\mathrm{CD}^{+}$and $\mathrm{CD} 8^{+}$epitopes known as Th2R and Th3R. ${ }^{42,44}$ The ' $R$ ' and ' $T$ ' components correspond to amino acids 207-395 on CSP of the 3D7 standard laboratory strain of $P$. falciparum. ${ }^{42,44,45}$ Fig. 3 shows a simplified representation of the 'RT' peptide chain. This is then fused to the N-terminal of the Hepatitis B surface (S) antigen (HBsAg), hence RTS. ${ }^{43}$ The second segment (S) is also a polypeptide chain and is 226 amino acids in length; it is an unfused $\mathrm{S}$ antigen which corresponds to HBsAg. ${ }^{42}$ These recombinant proteins self-assemble into virus-like composite particulates, facilitating increased uptake and expression by antigen-presenting cells. ${ }^{43,44}$

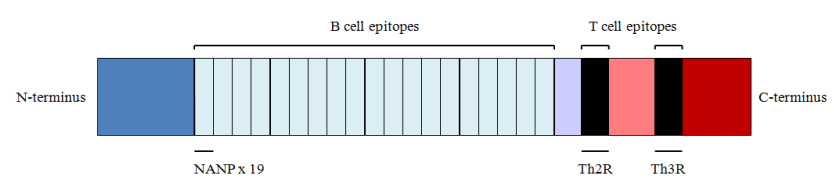

Fig. 3. Schematic representation of the ' $R T$ ' section of the RTS,S construct.

HBsAg is exploited for its strong cell-mediated and humoral immunogenicity; this property is effectively a secondary boost to the immune response which then has a primary effect on a sporozoite challenge. ${ }^{46}$ Moreover, the use of HBsAg stimulates immunity to Hepatitis B as well, making this a potentially bivalent vaccine. ${ }^{10,41}$

\subsection{Immune Response that Underpins RTS,S Design}

The mechanisms involved in naturally acquired pre-erythrocytic stage immunity remain imprecisely defined. ${ }^{47}$ Nonetheless, the first line of defence is known to be antibody production by $\mathrm{B}$ cells that targets newly inoculated sporozoites following recognition of the repeat 
tetra-peptide. ${ }^{48}$ The antibodies are primarily polyclonallyproduced non-specific immunoglobulin (Ig)M and IgG but a minor proportion, around $5 \%$, are species- or stage-specific and can interact with more of the parasite antigens. ${ }^{49}$ The time for the immune system to act on sporozoites before they infect hepatocytes is brief, and they are rarely cleared effectively. Once hepatocytes are infected cellular immune responses take over, which involve $\mathrm{CD}^{+}$and $\mathrm{CD} 8^{+} \mathrm{T}$ cells.

$\mathrm{CD}^{+} \mathrm{T}$ cells are implicated in the response to intrahepatocyte infection through several mechanisms. ${ }^{48,50}$ One triggers cytolytic activity via recognition of infected cells displaying parasite fragments associated with major histocompatibility complex class I. ${ }^{51}$ Recognition induces secretion of cytotoxins and perforins, which cause cell death, thereby killing the parasite. This function gives rise to its alternative name of cytotoxic $\mathrm{T}$ cells; however, $\mathrm{CD} 8^{+} \mathrm{T}$ cells can also produce cytokines, notably interferon gamma $(\mathrm{IFN}-\gamma)^{51}$

IFN- $\gamma$ demonstrates both immunostimulatory and immunomodulatory properties and its production is considered to play a more significant role than cytolytic activity toward infected hepatocytes. ${ }^{48,50}$ One particular mechanism of action is based on induction of the nitric oxide pathway, which is viewed as mainly responsible for destroying infected hepatocytes. ${ }^{50,52}$ Although $\mathrm{CD} 8^{+} \mathrm{T}$ cells are important, quantities in sporozoite- infected persons are insufficient to account for IFN- $\gamma$ concentrations detected. ${ }^{42}$ Other IFN- $\gamma$-producing cells are therefore principally responsible for its production; $\mathrm{CD}^{+} \mathrm{T}$ cells, natural killer cells, natural killer $\mathrm{T}$ cells and $\gamma \delta \mathrm{T}$ cells (a rare form of $\mathrm{T}$ lymphocyte). ${ }^{47,48}$ In fact, $\mathrm{CD}^{+} \mathrm{T}$ cells secrete the highest levels of IFN- $\gamma$ and studies in mice have shown $\mathrm{CD}^{+} \mathrm{T}$ cells (mainly $\mathrm{T}$ helper 1; Th1) to be essential to control parasitaemia. ${ }^{43}$ Furthermore, while IFN- $\gamma$ levels are preserved by depletion of $\mathrm{CD}^{+} \mathrm{T}$ cells they are dramatically reduced upon depletion of $\mathrm{CD}^{+} \mathrm{T}$ cells. ${ }^{44}$ These observations were made during a study involving RTS,S and help to explain the reasoning underpinning the design of the construct.

\subsection{Mechanism of Action of RTS,S}

RTS,S functions in two ways to elicit an immune response against a malaria infection (Fig. 4). First, it induces antibody-producing $\mathrm{B}$ cells by mimicking the repeat tetra-peptide of CSP. ${ }^{40,53}$ The subsequent B cell proliferation and differentiation blocks sporozoite entry into hepatocytes. This induction acts effectively as an immune booster because, as discussed, the immune system alone would rarely clear all inoculated sporozoites. The second approach is by induction of elevated levels of IFN- $\gamma$ through stimulating IFN- $\gamma$ producing Th1 $\mathrm{CD}^{+} \mathrm{T}$ cells that recognise specific $\mathrm{T}$ cell epitopes on the RTS construct. ${ }^{48,50}$ To a lesser extent it also induces $\mathrm{CD}^{+} \mathrm{T}$ cells. ${ }^{54}$ As IFN- $\gamma$ is involved in inhibiting parasite development within hepatocytes its production further enhances the vaccine's effectiveness. RTS,S targets only conserved antigens in order to avoid exerting a selection pressure for genetic mutation which could produce parasite resistance.

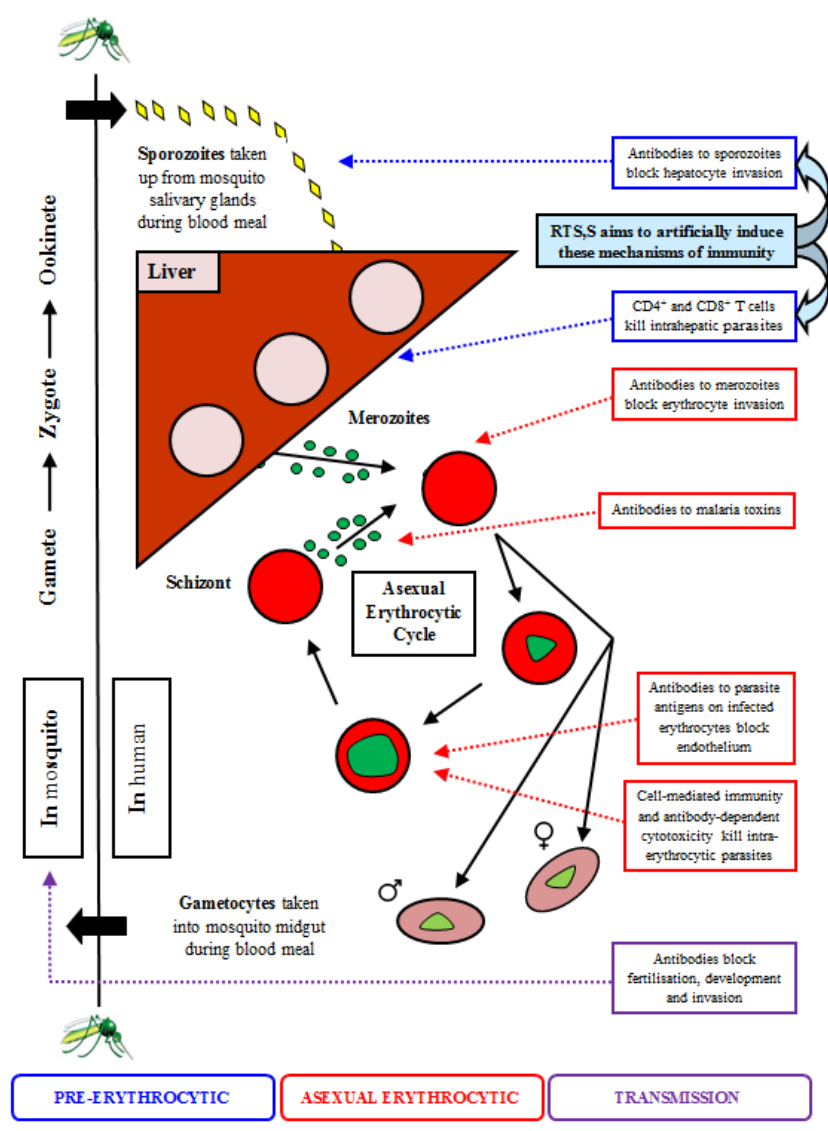

Fig. 4. Schematic diagram of the mechanisms of immunity to different life cycle stages of P. falciparum, highlighting those against the pre-erythrocytic parasite that RTS,S aims to induce.

Sporozoites are not especially immunogenic and, due to its close relation to CSP, the same is true of RTS,S. Consequently, an adjuvant system is needed to boost immunogenicity, the most promising of which has been using AS01 and AS02. These are proprietary formulations of GSK's AS class of adjuvant. AS01 utilises liposomes combined with immuno-stimulants 3-O-deacylated monophosphoryl lipid A and portion 21 (QS-21) of Quillaja saponaria, a plant native to South America. ${ }^{53,55}$ AS02 uses water-in-oil in lieu of liposomes but retains the same immunostimulants. These adjuvants boost antibody and $\mathrm{T}$ cell responses, hence escalating cell-mediated immunity. ${ }^{56} \mathrm{~A}$ specific benefit is their capacity to stimulate Th1 rather than $\mathrm{Th} 2 \mathrm{CD}^{+} \mathrm{T}^{\mathrm{T}}$ cells. ${ }^{53}$ This is advantageous because the Th2 subset does not produce IFN- $\gamma$.

The immune system has the capacity to remove sporozoites from the blood and to prevent development within hepatocytes; however, it is not failsafe. It is not understood completely why only partial immunity to malaria is induced but it has been theorised that the shedding of CSP-antibody complexes may act to avoid detection. ${ }^{57}$ If RTS,S is successful, circumvention of this problem may be achieved.

\section{RTS,S/AS01 Phase III Clinical Trials}


Of over 20 vaccine projects in clinical trials at the end of 2014, the progress of RTS,S/AS01, currently in well-advanced phase III clinical screening, is arguably 5-10 years ahead of other candidate vaccines. ${ }^{36}$ This is being performed in more than 15,000 infant and young children in seven sub-Saharan African nations: Burkina Faso, Gabon, Ghana, Kenya, Malawi, Mozambique and Tanzania. ${ }^{58}$ Different locations were selected in order to facilitate evaluation of the vaccine's effectiveness under a range of conditions of malaria transmission. Of the two age groups studied, infants received three doses of RTS,S/AS01 together with other standard childhood vaccines at 6,10 and 14 weeks of age. Older children were aged between 5-17 months at first vaccine administration.

\subsection{Early Indicators of Efficacy of RTS,S/ASO1 Vaccine Protection}

Initial results from the phase III trial were published in October 2011 for children aged 5-17 months at first immunization. ${ }^{59}$ This showed an overall reduction of $55 \%$ in all clinical episodes of $P$. falciparum infection over the 12 months follow-up period, with an estimated $47 \%$ efficacy against severe, life-threatening cases in this age group. Data for children vaccinated at 6-14 weeks old, when co-administered with other vaccines, were released in November $2012 .^{60}$ Estimated overall efficacy over 12 months of follow-up was 33\% for all malaria episodes, and 37\% for severe infection.

There is evidence in both age groups that protection lessens over the year following vaccination, and it is not yet known how long protection extends beyond this time. Moreover, whether or not a booster dose is needed to enhance protection remains to be determined. The implications of the apparent difference in level of protection afforded by RTS,S according to age of the recipient include the requirement for a detailed assessment of the feasibility, safety and effectiveness of possible immunization strategies and regimens for this vaccine. No data are available yet to indicate if the degree of protection varies between field sites with varying intensities of malaria transmission. Further information on all these matters should be available soon following the imminent completion of the phase III trial.

An in-depth analysis is necessary to investigate reasons for the apparent reduced efficacy when infants rather than older children are inoculated with RTS,S. Interference by co-administered vaccines, maternally acquired antibodies, intensity and seasonality of transmission are each possible causative factors. A preliminary finding is that lesser immune responses are evoked by the vaccine in infants aged 6-14 weeks compared to children aged 5-17 months.

\subsection{Predicted Availability for African Children of RTS,S/AS01 Vaccine}

If complete evaluation of the present phase III trial of RTS,S shows sufficient indication of a protective effect against $P$. falciparum, arguably it could be considered a 'first generation' malaria vaccine. ${ }^{61,62}$ This means recognition of RTS,S as partially effective, reducing the number of cases of malaria in vaccinated children, but not preventing all episodes of the disease. Prior to it being recommended for incorporation into immunization programs in endemic African countries, information is required on how long lasting are the vaccine's effects, the efficacy of a booster dose and what is the protection level in different settings.

Any proposed vaccine would require licensure through national regulatory authorities, evaluation of which becomes relevant when sufficient safety, immunogenicity and efficacy data are available for the target population for immunization. Requirements that would need to be met include: a WHO recommendation for use in a designated target population; WHO pre-qualification for a specific vaccine formulation from a specified manufacturer to ensure international standards of quality, safety and efficacy are fulfilled (for territories wishing to be supplied by the United Nations, or which use WHO prequalification as the basis for procurement eligibility); and implementation by national public health agencies of an agreed program of vaccine delivery. ${ }^{61}$ The projected role a novel intervention may play in the context of existing preventive and treatment measures, combined with its affordability and cost-effectiveness, are two examples of the many factors supplementary to efficacy that will influence a country's decision on implementation. Based on existing understanding, and depending on the final trial results, a WHO recommendation for use and subsequent prequalification of RTS,S may occur as early as 2015. In this context it is greatly prescient that GlaxoSmithKline has recently applied to the European Medicines Agency for an initial regulatory review of RTS,S to evaluate its suitability for markets outside Europe, presumably primarily with Africa in mind. ${ }^{63}$

\section{Conclusion}

The demand for an effective, affordable vaccine against $P$. falciparum malaria mortality and morbidity and the associated negative socioeconomic impacts is a global public health priority. Proof of feasibility for a vaccine is based on two precepts. First, knowledge that repetitive exposure promotes naturally acquired non- sterile immunity, and second that sterile immunity can be induced using subunits, and indeed attenuated sporozoites. Bearing this in mind and considering the volume of supportive data, a malaria vaccine seems attainable within the next decade. This would be in accord with the Malaria Vaccine Technology Roadmap, published in 2006, through a collaboration of the leading international health organizations including the WHO, MVI, BAMGF and the Wellcome Trust. $^{23}$ This set a highly ambitious target to attain a vaccine by 2025 that demonstrates protective efficacy of more than $80 \%$ against clinical disease caused by $P$. falciparum and lasts for over four years. An intermediate measurable outcome is that by 2015 the vaccine should be $50 \%$ effective against severe disease and death and should last for a minimum of 12 months. 
Although RTS,S may prove to be the world's first licensed malaria vaccine, its performance in trials has not proved as strong as hoped or arguably required. Trials have yet to show that RTS,S can elicit herd immunity which is ultimately necessary to fulfil the NGOs' goal of malaria eradication. Furthermore, while it may induce sterile immunity, as with naturally acquired immunity, this is imperfect and in trial patients this waned eventually. Analysis of the full results of the phase III trial will go a considerable way to determine whether or not RTS,S has a viable future, at least in its present formulation. If deemed to be unsuccessful - and, since the results may not be clear cut, this will require consensus - other candidate vaccines will probably become the focus of attention. This begs the question of what is the minimum acceptable efficacy in trials for a vaccine to continue to commercialisation since even a modestly effective malaria vaccine would protect each year hundreds of thousands of people from disease and death. Failure, real or perceived, would reinforce the contention of some stakeholders in the malaria research community that vaccine development is less than optimal use of resources, which should be diverted into investment in existing low technology control measures. Putting to one side allocation of funds, these diverse intervention strategies complement each other so a pragmatic policymaker would be prudent to adopt a multifaceted approach with a vaccine as one of several tools at their disposal to reduce the global burden of $P$. falciparum.

\section{References}

[1] Moya A. \& Font E. (2004). Evolution: From Molecules to Ecosystems. Oxford: Oxford University Press.

[2] Singh B., Kim Sung L., Matusop A., Radhakrishnan A., Shamsul S.S., Cox-Singh J., Thomas A. \& Conway D.J. (2004). A large focus of naturally acquired Plasmodium knowlesi infections in human beings. Lancet, 363 (9414), 1017-1024.

[3] World Health Organization (2008). World Malaria Report 2008. Geneva: WHO.

[4] Breman J.G. (2009). Eradicating malaria. Science Progress, $92(1), 1-38$.

[5] U.S. Census Bureau (2011). International Programs - World POPClock Projection [online]. http://www.census.gov/ipc/ www/popclockworld.html. Accessed 24 November 2014.

[6] Hay S.I., Guerra C., Tatem A., Noor A. \& Snow R (2004). The global distribution and population at risk of malaria: past, present, and future. Lancet Infectious Diseases, 4 (6), 327-336.

[7] Guerra C.A., Gikandi P.W., Tatem A.J., Noor A.M., Smith D.L., Hay S.I. \& Snow R.W (2008). The limits and intensity of Plasmodium falciparum transmission: implications for malaria control and elimination worldwide. PLoS Medicine, 5 (2), e38.

[8] World Health Organization (2010). Malaria [online]. http://www.who.int/mediacentre/factsheets/fs094/en/. Accessed 24 November 2014.
[9] Malaria Vaccine Initiative (2010). The PATH Malaria Vaccine Initiative [online]. http://www.malariavaccines.org/ publications-factsheets.php. Accessed 24 November 2014.

[10] Malaria Vaccine Initiative (2007). Accelerating Progress Toward Malaria Vaccines [online]. http://www.malaria vaccines.org/files/080212_MVI_portfolio_bro_mvilogo_000. pdf. Accessed 24 November 2014.

[11] Sherman I.W. (1998). Malaria - Parasite Biology, Pathogenesis and Protection. Washington DC: ASM Press.

[12] Gallup J.L. \& Sachs J.D. (2001). The economic burden of malaria. American Journal of Tropical Medicine and Hygiene, 64 (1-2), 85-96.

[13] Targett G.A.T. \& Greenwood B.M. (2008). Malaria vaccines and their potential role in the elimination of malaria. Malaria Journal, 7, (suppl. 1), S10.

[14] Markell E.K., Voge M. \& John D.T. (1992). Medical Parasitology, $7^{\text {th }}$ edition. London: W.B. Saunders.

[15] Centers for Diseases Control (2011). DPDx - Malaria [online]. http://www.dpd.cdc.gov/DPDx!HTML/malaria.htm. Accessed 24 November 2014.

[16] Knell A.J. (1991). Malaria: a publication of the tropical programme of the Wellcome Trust. Oxford: Oxford University Press.

[17] Bruce-Chwatt L.J. (2002). Bruce-Chwatt's Essential Malariology, $4^{\text {th }}$ edition. London: Hodder Arnold.

[18] Mueller I., Galinski M.R., Baird K., Carlton J.M., Kochar D.K., Alonso P.L. \& del Portillo H.A. (2009). Key gaps in the knowledge of Plasmodium vivax, a neglected human malaria parasite. Lancet Infectious Diseases, 9 (9), 555-566.

[19] Greenwood B.M. (2008). Control to elimination: implications for malaria research. Trends in Parasitology, 24 (10), 449-454.

[20] Slutsker L. \& Kachur S.P. (2013). It is time to rethink tactics in the fight against malaria. Malaria Journal, 12, 140. doi:10.1186/1475-2875-12-140.

[21] Stevenson M.M. \& Zavala F. (2006). Immunology of malaria infections. Parasite Immunology, 28 (1-2), 1-4.

[22] Narasimhan V. \& Attaran A. (2003). Roll Back Malaria? The scarcity of international aid for malaria control. Malaria Journal, 2 (8), 1-8.

[23] Roadmap Working Group (2006). Malaria Vaccine Technology Roadmap [online]. http://www.malariavaccine roadmap.net/. Accessed 24 November 2014.

[24] Kurtis J.D., Mtalib R., Onyango F.K. \& Duffy P.E. (2001). Human resistance to Plasmodium falciparum increases during puberty and is predicted by dehydroepiandrosterone sulfate levels. Infection and Immunity, 69 (1), 123-128.

[25] Baird J.K., Jones T.R., Danudirgo E.W., Annis B.A., Bangs M.J., Basri H., Purnomo \& Masbar S. (1991). Age-dependent acquired protection against Plasmodium falciparum in people having two year exposure to hyperendemic malaria. American Journal of Tropical Medicine and Hygiene, 45 (1), 65-76.

[26] Baird J.K. (1998). Age-dependent characteristics of protection v. susceptibility to Plasmodium falciparum. Annals of Tropical Medicine and Parasitology, 92 (4), 367-390. 
[27] Smith T.A., Leuenberger R. \& Lengeler C. (2001). Child mortality and malaria transmission intensity in Africa. Trends in Parasitology 17 (3), 145-149.

[28] Taylor-Robinson A.W. (2010). Validity of modelling cerebral malaria in mice: argument and counter argument. Journal of Neuroparasitology. doi:10.4303/jnp/N100601.

[29] Kane E.G. \& Taylor-Robinson A.W. (2011). Prospects and pitfalls of pregnancy-associated malaria vaccination based on the natural immune response to Plasmodium falciparum VAR2CSA-expressing parasites. Malaria Research and Treatment. doi:10.4061/2011/764845.

[30] Taylor-Robinson A.W., Morley L.C. \& Kane E.G. (2013). Rationale for pregnancy-associated malaria vaccination predicated on antibody-mediated immunity to Plasmodium falciparum placenta-binding parasites. In: Vaccines: Benefits and Risks. iConcept Press, Sunnybank Hills, QLD, Australia, pp. 95-130.

[31] Abdel-Wahab A., Abdel-Muhsin A.M., Ali E., Suleiman S., Ahmed S., Walliker D. \& Babiker H.A. (2002). Dynamics of gametocytes among Plasmodium falciparum clones in natural infections in an area of highly seasonal transmission. Journal of Infectious Diseases, 185 (12), 1838-1842.

[32] Schofield L. \& Mueller I. (2006). Clinical immunity to malaria. Current Molecular Medicine, 6 (2), 205-221.

[33] Taylor-Robinson A.W. (2002). A model of development of acquired immunity to malaria in humans living under endemic conditions. Medical Hypotheses, 58 (2), 148-156.

[34] Malaria Vaccine Initiative (2004). Clinical Trials: Crucial Steps on the Road to a Malaria Vaccine [online]. $\mathrm{http}: / /$ wwwmalariavaccine.org/files/MVI_clinical_trials paper.pdf. Accessed 24 November 2014.

[35] Morley L.C. \& Taylor-Robinson A.W. (2012). Understanding how Plasmodium falciparum binds to the placenta and produces pathology provides a rationale for pregnancy- associated malaria vaccine development. Open Vaccine Journal, 5, 8-27. doi: 10.2174/1875035401205010008.

[36] Denny J.W.L. \& Taylor-Robinson A.W. (2012). The development pathway of the most advanced candidate vaccine against malaria, RTS,S. Journal of Malaria Research, 2 (1), $1-29$.

[37] Malaria Vaccine Initiative (2008). Fighting malaria today and tomorrow [online]. http://www.malariavaccines.org/ publications-factsheets.php. Accessed 24 November 2014.

[38] World Health Organization (2009). World Malaria Report 2009. Geneva: WHO.

[39] Hill A.V.S. (2006). Pre-erythrocytic malaria vaccines: towards greater efficacy. Nature Reviews Immunology 6 (1), 21-32.

[40] Mikolajczak S.A., Aly A.S.I. \& Kappe, S.H.I. (2007). Pre-erythrocytic malaria vaccine development. Current Opinion in Infectious Diseases, 20 (5), 461-466.

[41] Malaria Vaccine Initiative (2006). Fact Sheet: RTS,S Malaria Vaccine Clinical Trials. http://www.malaria vaccine.org/ files/FS_RTSS_FINAL.pdf. Accessed 24 November 2014.

[42] Ballou W.R., Arevalo-Herrera M., Carucci D., Richie T.L., Corradin G., Diggs C., Druilhe P., Giersing B.K., Saul A., Heppner D.G., Kester K.E., Lanar D.E., Lyon J., Hill A.V.S.,
Pan W. \& Cohen J.D. (2004). Update on the clinical development of candidate malaria vaccines. American Journal of Tropical Medicine and Hygiene, 71 (suppl. 2), S239-247.

[43] Ballou W.R. \& Cahill C.P. (2007). Two decades of commitment to malaria vaccine development: Glaxo SmithKline biologicals. American Journal of Tropical Medicine and Hygiene, 77 (6), 289-295.

[44] Stoute J.A., Kester K.E., Krzych U., Wellde B.T., Hall T., White K., Glenn G., Ockenhouse C.F., Garcon N., Schwenk R., Lanar D.E., Sun P., Mornin P., Wirtz R.A., Golenda C., Slaoui M., Wortmann G., Holland C., Dowler M., Cohen J. \& Ballou W.R. (1998). Long-term efficacy and immune responses following immunization with the RTS,S malaria vaccine. Journal of Infectious Diseases, 178 (4), 1139-1144.

[45] Waitumbi J.N., Anyona S.B., Hunja C.W., Kifude C.M., Polhemus M.E., Walsh D.S., Ockenhouse C.F., Heppner D.G., Leach A., Lievens M., Ballou W.R., Cohen J.D. \& Sutherland C.J. (2009). Impact of RTS,S/AS02(A) and RTS,S/AS01(B) on genotypes of $P$. falciparum in adults participating in a malaria vaccine clinical trial. PLoS One, 4 (11), e7849.

[46] Ambroise-Thomas P. (1997). Vaccination against malaria. Disappointments and hopes. Bulletin de l'Académie Nationale de Médecine, 181 (8), 1637-1648.

[47] Doolan D.L. \& Martinez-Alier N. (2006). Immune response to pre-erythrocytic stages of malaria parasites. Current Molecular Medicine, 6 (2), 169-185.

[48] Plebanski M. \& Hill A.V.S. (2000). The immunology of malaria infection. Current Opinion in Immunology, 12 (4), 437-441.

[49] Perlmann P. \& Troye-Blomberg M. (2002). Malaria Immunology, $2^{\text {nd }}$ edition. Basel: Karger.

[50] Reece W.H., Pinder M., Gothard P.K., Milligan P., Bojang K., Doherty T., Plebanski M., Akinwunmi P., Everaere S., Watkins K.R., Voss G., Tomieporth N., Alloueche A., Greenwood B.M., Kester K.E., McAdam K.P., Cohen J. \& Hill A.V.S. (2004). A CD4 ${ }^{+}$T-cell immune response to a conserved epitope in the circumsporozoite protein correlates with protection from natural Plasmodium falciparum infection and disease. Nature Medicine, 10 (4), 406-410.

[51] Cruse J.M. \& Lewis R.E. (2004). Atlas of Immunology, $2^{\text {nd }}$ edition. London: CRC Press.

[52] Malaria Vaccine Initiative (2009). Sanaria PfSPZ malaria vaccine candidate [online]. http://www.malariavaccines.org/ publications-factsheets.php. Accessed 24 November 2014.

[53] Richie T. High road, low road? (2006). Choices and challenges on the pathway to a malaria vaccine. Parasitology 133, (suppl.), S113-144.

[54] Sun, P., Schwenk R., White K., Stoute J.A., Cohen J., Ballou W.R., Voss G., Kester K.E., Heppner D.G. \& Krzych U. (2003). Protective immunity induced with malaria vaccine, RTS,S, is linked to Plasmodium falciparum circumsporozoite protein-specific $\mathrm{CD}^{+}$and $\mathrm{CD} 8^{+} \mathrm{T}$ cells producing IFN- $\gamma$. Journal of Immunology, 171 (12), 6961-6967.

[55] World Health Organization (2011). WHO - Parasitic Diseases [online]. http://www.who.int/vaccine_research/diseases/soa parasitic/en/index 4. html\#pre-erythrocytic\% 20 vaccines. Accessed 24 November 2014. 
[56] Antigenics Inc. (2010). QS-21 immune adjuvant [online]. http://www.antigenics.com/products/tech/qs2. Accessed 24 November 2014.

[57] Stewart M.J. \& Vanderberg J.P. (1988). Malaria sporozoites leave behind trails of circumsporozoite protein during gliding motility. Journal of Protozoology, 35 (3), 389-393.

[58] Leach A., Vekemans J., Lievens M., Ofori-Anyinam O., Cahill C., Owusu-Agyei S., Abdulla S., Macete E., Njuguna P., Savarese B., Loucq C., Ballou W.R. \& Clinical Trials Partnership Committee (2011). Design of a phase III multicenter trial to evaluate the efficacy of the RTS,S/AS01 malaria vaccine in children across diverse transmission settings in Africa. Malaria Journal, 10, 224 . doi: 10.1186/1475-2875-10-224

[59] Agnandji S.T., Lell B., Soulanoudjingar S.S., Fernandes J.F., Abossolo B.P., Conzelmann C., Methogo B.G., Doucka Y., Flamen A., Mordmüller B., Issifou S., Kremsner P.G., Sacarlal J., Aide P., Lanaspa M., Aponte J.J., Nhamuave A., Quelhas D., Bassat Q., Mandjate S., Macete E., Alonso P., Abdulla S., Salim N., Juma O., Shomari M., Shubis K., Machera F., Hamad A.S., Minja R., Mtoro A., Sykes A., Ahmed S., Urassa A.M., Ali A.M., Mwangoka G., Tanner M., Tinto H., D'Alessandro U., Sorgho H., Valea I., Tahita M.C., Kaboré W., Ouédraogo S., Sandrine Y., Guiguemdé R.T., Ouédraogo J.B., Hamel M.J., Kariuki S., Odero C., Oneko M., Otieno K., Awino N., Omoto J., Williamson J., Muturi-Kioi V., Laserson K.F., Slutsker L., Otieno W., Otieno L., Nekoye O., Gondi S., Otieno A., Ogutu B., Wasuna R., Owira V., Jones D., Onyango A.A., Njuguna P., Chilengi R., Akoo P., Kerubo C., Gitaka J., Maingi C., Lang T., Olotu A., Tsofa B., Bejon P., Peshu N., Marsh K., Owusu-Agyei S., Asante K.P., Osei-Kwakye K., Boahen O., Ayamba S., Kayan K., Owusu-Ofori R., Dosoo D., Asante I., Adjei G., Adjei G., Chandramohan D., Greenwood B., Lusingu J., Gesase S., Malabeja A., Abdul O., Kilavo H., Mahende C., Liheluka E., Lemnge M., Theander T., Drakeley C., Ansong D., Agbenyega T., Adjei S., Boateng H.O., Rettig T., Bawa J., Sylverken J., Sambian D., Agyekum A., Owusu L., Martinson F., Hoffman I., Mvalo T., Kamthunzi P., Nkomo R., Msika A., Jumbe A., Chome N., Nyakuipa D., Chintedza J., Ballou W.R., Bruls M., Cohen J., Guerra Y., Jongert E., Lapierre D., Leach A., Lievens M., Ofori-Anyinam O., Vekemans J., Carter T., Leboulleux D., Loucq C., Radford A., Savarese B., Schellenberg D., Sillman M., Vansadia P. \& RTS,S Clinical Trials Partnership (2011). First results of phase 3 trial of
RTS,S/AS01 malaria vaccine in African children. New England Journal of Medicine, 365 (20), 1863-1875.

[60] RTS,S Clinical Trials Partnership, Agnandji S.T., Lell B., Fernandes J.F., Abossolo B.P., Methogo B.G., Kabwende A.L., Adegnika A.A., Mordmüller B., Issifou S., Kremsner P.G., Sacarlal J., Aide P., Lanaspa M., Aponte J.J., Machevo S., Acacio S., Bulo H., Sigauque B., Macete E., Alonso P., Abdulla S., Salim N., Minja R., Mpina M., Ahmed S., Ali A.M., Mtoro A.T., Hamad A.S., Mutani P., Tanner M., Tinto H., D'Alessandro U., Sorgho H., Valea I., Bihoun B., Guiraud I., Kaboré B., Sombié O., Guiguemdé R.T., Ouédraogo J.B., Hamel M.J., Kariuki S., Oneko M., Odero C., Otieno K., Awino N., McMorrow M., Muturi-Kioi V., Laserson K.F., Slutsker L., Otieno W., Otieno L., Otsyula N., Gondi S., Otieno A., Owira V., Oguk E., Odongo G., Woods J.B., Ogutu B., Njuguna P., Chilengi R., Akoo P., Kerubo C., Maingi C., Lang T., Olotu A., Bejon P., Marsh K., Mwambingu G., Owusu-Agyei S., Asante K.P., Osei-Kwakye K., Boahen O., Dosoo D., Asante I., Adjei G., Kwara E., Chandramohan D., Greenwood B., Lusingu J., Gesase S., Malabeja A., Abdul O., Mahende C., Liheluka E., Malle L., Lemnge M., Theander T.G., Drakeley C., Ansong D., Agbenyega T., Adjei S., Boateng H.O., Rettig T., Bawa J., Sylverken J., Sambian D., Sarfo A., Agyekum A., Martinson F., Hoffman I., Mvalo T., Kamthunzi P., Nkomo R., Tembo T., Tegha G., Tsidya M., Kilembe J., Chawinga C., Ballou W.R., Cohen J., Guerra Y., Jongert E., Lapierre D., Leach A., Lievens M., Ofori-Anyinam O., Olivier A., Vekemans J., Carter T., Kaslow D., Leboulleux D., Loucq C., Radford A., Savarese B., Schellenberg D., Sillman M. \& Vansadia P. (2012). A phase 3 trial of RTS,S/AS01 malaria vaccine in African infants. New England Journal of Medicine, 367 (24), 2284-2295.

[61] Birkett A.J., Moorthy V.S., Loucq C., Chitnis C.E. \& Kaslow D.C. (2013). Malaria vaccine R\&D in the decade of vaccines: breakthroughs, challenges and opportunities. Vaccine 31, (suppl. 2), B233-243.

[62] Denny J.W.L. \& Taylor-Robinson A.W. (2012). Progress with RTS,S - the most advanced candidate vaccine against malaria. In: Peterson A.M. \& Calamandrei G.E. (eds.), Malaria: Etiology, Pathogenesis and Treatments. Nova Science Publishers, Hauppauge, NY, USA, pp. 39-67.

[63] Willyard C. (2014). Malaria vaccine, destined for Africa, seeks OK from Europe. Nature Medicine 20 (9), 968-969. 